\title{
KAJIAN KEBIJAKAN PEMANFAATAN OBAT TRADISIONAL DI FASILITAS PELAYANAN KESEHATAN PADA ERA JAMINAN KESEHATAN NASIONAL
}

\section{The Utilization of Traditional Medicines in Health Service Facilities in the Era of National Health Assurance: A Policy Study}

\author{
Lucie Widowati, Ondri Dwi Sampurno, Hadi Siswoyo, Rini Sasanti, Nurhayati, Delima \\ Puslitbang Sumber Daya dan Pelayanan Kesehatan - Badan Litbang Kesehatan \\ Naskah masuk: 21 Juni 2020 Perbaikan: 19 September 2020 Layak terbit: 19 Oktober 2020 \\ https://doi.org/10.22435/hsr.v23i4.3379
}

\begin{abstract}
ABSTRAK
Sejak dibentuknya Badan Pengelola Jaminan Sosial (BPJS),terjadi penurunan permintaan pasien atas layanan obat tradisional di fasilitas pelayanan kesehatan (fasyankes). Tujuan menganalisis berbagai aspek, situasi /kondisi pemanfaatan obat tradisional dalam pelayanan di fasyankes. Mengkaji peraturan perundang-undangan dan kebijakan terkait pemanfaatan obat tradisional di fasyankes, dan melakukan wawancara mendalam dengan nara sumber relevan di fasilitas pelayanan kesehatan dan dinas kesehatan terpilih (Kota Surakarta dan Semarang). Analisis dilakukan secara deskriptif dan induktif. Terdapat lebih dari 20 peraturan perundang-undangan dan kebijakan terkait pemanfaatan obat tradisional di fasyankes. Aspek yang dikaji adalah pelayanan, implementasi jaminan Obat Tradisional (OT) dengan BPJS, kesiapan klinisi dan dukungan pemerintah. Adanya JKN menyebabkan penggunaan OT mengalami penurunan drastis, adanya pengaturan dana alokasi khusus (DAK) dan kapitasi, tidak dimanfaatkan fasyankes. Komite medik rumah sakit, puskesmas serta dinas kesehatan membutuhkan adanya daftar obat tradisional yang dapat digunakan di fasyankes yang ditetapkan pemerintah. Daftar obat tradisional diharapkan berisi pilihan obat tradisional untuk upaya preventif, promotif, kuratif ringan dan paliatif sebagai komplemen maupun sebagai adjuvan. Pelayanan dengan obat tradisional masuk jalur upaya preventif, promotif atau kuratif ringan baik sebagai adjuvant maupun komplemen dengan obat konvensional. Pembiayaan obat tradisional dapat dilakukan dengan DAK, dana Kapita si atau APBN II, namun belum dimanfaatkan. Kondisi ini karena kurangnya political will dari stake holder dan belum adanya acuan standar Formularium Obat Tradisional, terutama jika kemudian hari dapat dijamin oleh BPJS. Masih dibutuhkan adanya regulasi ketetapan menteri bahwa fasyankes wajib melakukan pelayanan dengan obat tradisional.
\end{abstract}

Kata Kunci: Pemanfaatan, Obat Tradisional, JKN

\section{ABSTRACT}

Since the establishment of the Healthcare Social Security Agency (BPJS), there has been a low demand of patient demand for traditional medicine (TM) services in health care facilities. This study examined various aspects, situations/ conditions and the potential use of TM in health facilities. Secondary sources, such as policies and regulations, and indepth interviews, became the primary data. Those who in charge of the BPJS program was the key informant. The study focused on informants, particularly either Semarang or Surakarta. This study analysed the data, both descriptively and inductively. The aspects examined were services, the implementation of OT guarantees with BPJS, clinicians' readiness and government supports. The existence of JKN implies the use of OT to decrease dramatically. The health facilities did not fully utilise the presence of special allocation funds (DAK) and capitation arrangements. The list of TM was to contain the choices for preventive, promotive, curative, and palliative efforts either a compliment or an adjuvant. TM services involved in the path of preventive, promotive or curative actions either as an adjuvant, or complement with conventional medicine. TM financing may be from DAK, capitation funds or APBN II; however, these sources did not optimise yet. This condition happened due to the lack of political will from stakeholders, as well as the absence of standard reference for

Korespondensi:

Lucie Widowati

Puslitbang Sumber Daya dan Pelayanan Kesehatan - Badan Litbang Kesehatan

E-mail: Luciewidowati@yahoo.com 
Kajian Kebijakan Pemanfaatan Obat Tradisional (Lucie Widowati, dkk.)

the Traditional Medicine Formulary, especially BPJS enrollment by the future. Therefore, the Ministry of Health RI has to issue a decree for health facilities obliged to provide services with traditional medicines.

Keywords: Utilization, Traditional Medicines, National Health Insurance

\section{PENDAHULUAN}

Peraturan Presiden No. 72 tahun 2012 tentang Sistem Kesehatan Nasional, menyatakan bahwa pelayanan kesehatan meliputi peningkatan, pencegahan, pengobatan dan pemulihan, baik pelayanan kesehatan konvensional maupun pelayanan kesehatan tradisional (yankestrad). Dalam rencana strategis WHO tahun 2001, salah satu poin adalah dilaksanakannya integrasi obat tradisional (OT) sehingga OT dapat dilayani di fasilitas pelayanan kesehatan (World Health Organization, 2002). Suatu survey pelayanan herbal oleh dokter di Pulau Jawa yang dilakukan tahun 2010 menunjukkan bahwa OT menjadi pilihan masyarakat dan telah dilayani oleh 144 dokter baik di rumah sakit (RS), puskesmas maupun pada praktik mandiri. Dari penelitian ini didapatkan data bahwa sebagian besar dokter (76,9 \%) telah melakukan praktik dengan OT antara 1 hingga 10 tahun (Delima et al., 2012).Alasan utama dokter memberikan jamu pada pasien adalah sebagai terapi komplementer sebanyak 88,9\% dan karena memenuhi permintaan pasien sebanyak 50 \% (Delima et al., 2012).

Pada tahun 2011 dibentuk badan hukum yang menyelenggarakan program Jaminan Kesehatan Nasional (JKN) melalui Undang-undang No. 24 Tahun 2011 tentang BPJS. Hasil penelitian Suharmiati menunjukkan bahwa sebelum adanya BPJS, permintaan OT oleh pasien di Puskesmas cukup banyak dan bersedia mengeluarkan dana untuk membayar OT yang diberikan tenaga medis. Kondisi ini berubah, setelah adanya jaminan kesehatan dengan BPJS, di mana pelayanan OT di fasyankes menurun karena pasien memilih menerima obat tanpa mengeluarkan biaya (Suharmiati et al., 2018). Sementara produksi OT semakin meningkat setiap tahun sebesar 30\% (Media Indonesia, 2020). Berdasarkan data BPOM tahun 2017 jumlah produk OT terdapat lebih dari 12.000 jenis, 64 jenis produk sebagai obat herbal terstandar (OHT) dan 20 jenis produk sebagai fitofarmaka. Upaya untuk integrasi OT difasyankes juga merupakan sasaran akhir dari roadmap jamu nasional 2011-2025 (Kemenko Perekonomian, 2011). Kajian ini bertujuan untuk menganalisis aspek dan kondisi pemanfaatan obat tradisional di fasyankes dalam era JKN.

\section{METODE}

Bahan kajian adalah peraturan perundangundangan dan kebijakan terkait pemanfaatan obat tradisional di fasyankes. Kajian dilaksanakan tahun 2018, dengan melakukan inventarisasi peraturan perundang-undangan dan kebijakan terkait pemanfaatan obat tradisional di fasyankes. Gambaran pelayanan obat tradisional dan situasi jaminan obat tradisional setelah adanya JKN dikembangkan lebih lanjut melalui wawancara mendalam kepada nara sumber. Nara sumber adalah direktur dan komite medik di rumah sakit, kepala puskesmas dan kepala dinas kesehatan di lokasi terpilih, menggunakan instrumen wawancara. Lokasi kajian dibatasi dan dipilih berdasarkan informasi terkait pengembangan dan pemanfaatan OT yaitu di Surakarta (puskesmas, dinas kesehatan) dan Semarang (rumah sakit pemerintah dan rumah sakit non pemerintah).

\section{Analisis}

Analisis dilakukan secara deskriptif dan induktif untuk mengidentifikasi pemanfaatan obat tradisional di fasyankes di era JKN

\section{Etik}

Persetujuan etik dikeluarkan oleh Komisi Etik Penelitian Kesehatan, Badan Penelitian dan Pengembangan Kesehatan (KEPK-BPPK), dengan No. LB.02.01/2/KE.182/2018.

\section{HASIL}

\section{Peraturan terkait pelayanan obat tradisional}

Fitofarmaka merupakan bentuk sediaan obat tradisional dengan evidence base. Jumlah yang beredar cukup terbatas, karena kurang diminati oleh industriy. Untuk menghasilkan fitofarmaka dibutuhkan biaya yang tidak sedikit, namun dirasakan belum memberi keuntungan bagi industri. Hal ini karena belum adanya jaminan dari pemerintah bahwa fitofarmaka akan dimanfaatkan dalam pelayanan di fasyankes. Sementara adanya Instruksi Presiden Nomor 6 Tahun 2016 tentang Percepatan pengembangan Industri Farmasi, industri harus mendorong diri untuk mengembangkan produk 
fitofarmaka. Seharusnya ada dukungan dari pemerintah secara sinergis, agar fitofarmaka segera dapat dimanfaatkan dalam pelayanan kesehatan.

Ketua Komisi IX DPR RI pada kunjungannya ke B2P2TOOT bulan Agustus 2017, mengatakan "ke depannya, sistem pelayanan kesehatan akan dibuat lebih ramah terhadap obat obat tradisional. Diharapkan pasien nantinya bisa memilih untuk mendapatkan pelayanan obat konvensional atau obat berbahan herba tradisional." tuturnya.

KMK No. 121/2008 tentang Standar Pelayanan Medik Herbal, menyebutkan bahwa sarana pelayanan medik herbal dapat dilakukan di praktik dokter perorangan/kelompok; puskesmas dan rumah sakit. Pelayanan herbal dilakukan oleh dokter, dokter gigi, dan dokter spesialis dengan pendidikan herbal dasar yang mempunyai sertifikat kompetensi herbal. Data PERSI tahun 2013 menyatakan bahwa sebanyak 56 rumah sakit (RS) di 18 provinsi sudah melayani pengobatan non konvensional seperti pengobatan alternatif atau OT di samping pengobatan medis konvensional. Berdasarkan Surat Keputusan Direktur Jenderal Bina Pelayanan Medik telah ditetapkan 12 (dua belas) Rumah Sakit Pendidikan yang melaksanakan pelayanan pengobatan komplementer tradisional-alternatif (Alawiya et al., 2017).

Upaya pemerintah untuk memasukkan OT dalam pelayanan tertuang dalam PP No. 103 tahun 2014 tentang pelayanan kesehatan tradisional, yang membagi pelayanan dengan ramuan dan keterampilan dalam fasilitas pelayanan tradisional komplementer maupun dalam suatu sistem integrasi dengan fasyankes. Integrasi dapat dilakukan di Pelayanan kesehatan primer maupun rujukan. Pelayanan tingkat kesehatan primer, yakni integrasi OT bersama obat konvensional, untuk pelayanan promotif maupun preventif. Pelayanan pada tingkat rujukan, dapat dilakukan pelayanan di rumah sakit, baik integrasi tenaga komplementer terhadap kedokteran konvensional, maupun integrasi OT dengan obat konvensional (Siswanto, 2018).

Keberadaan PP No. 103 tahun 2014 ternyata belum sepenuhnya dapat mengangkat OT masuk dalam pelayanan. Sejak tahun 2011 Indonesia menerapkan Jaminan Kesehatan Nasional. Perpres No. 12 tahun 2013 tentang Jaminan Kesehatan, menyebutkan bahwa pelayanan yang tidak dapat dijamin oleh BPJS, diantaranya adalah pengobatan komplementer, alternatif dan tradisional, termasuk akupuntur, shin she, chiropractic, yang belum dinyatakan efektif berdasarkan penilaian teknologi kesehatan (Health Technology Assessment/HTA). Lebih lanjut dinyatakan bahwa dalam rangka menjamin mutu dan biaya, menteri bertanggung jawab atas HTA serta pertimbangan klinis (clinical advisory). Hingga saat ini peran Komite HTA terhadap yankestrad masih terbatas pada pemanfaatan akupunktur yang semula dijamin BPJS, dan kemudian hanya berlaku pada akupunktur medis di Fasilitas Kesehatan Rujukan Tingkat Lanjutan ( FKRTL) (Permenkes nomor 28 Tahun 2014).

Peraturan terkait lain adalah Permenkes HK.0.02/MENKES/068/I/2010 tentang Kewajiban Menggunakan Obat Generik di Fasilitas Pelayanan Kesehatan Pemerintah. Ketersediaan obat generik harus dalam jumlah dan jenis yang cukup, terjangkau oleh masyarakat serta terjamin mutu dan keamanannya. Peraturan yang disebutkan di atas, menjadi kendala bahwa OT belum dapat dilayankan di fasyankes.

\section{Pengadaan OT di fasyankes}

Undang-Undang Nomor 33 Tahun 2004 tentang Perimbangan Keuangan antara Pemerintah Pusat dan Pemerintah Daerah, mengamanatkan Dana Alokasi Khusus (DAK) sebagai salah satu sumber pembangunan kesehatan. Undang-Undang Nomor 23 Tahun 2014 tentang Pemerintahan Daerah, pasal 298 menyebutkan belanja DAK diprioritaskan untuk mendanai kegiatan fisik dan nonfisik, dan sebagai penanggung jawab pengelolaan DAK Bidang Kesehatan berada di tangan Bupati/ Walikota. Petunjuk Teknis DAK tertuang dalam Permenkes Nomor 82 Tahun 2015, dengan pelaksana Kepala Dinas Kesehatan dan atau Direktur Rumah Sakit Umum Daerah. Dalam hal obat dan bahan medis habis pakai (BMHP) yang dibutuhkan tidak tercantum dalam acuan tersebut di atas, maka dapat digunakan obat dan BMHP lain (termasuk jamu, OHT dan fitofarmaka) secara terbatas sesuai indikasi medis dan pelayanan kesehatan dengan persetujuan Kepala Dinas Kesehatan Kabupaten/ Kota. Pilihan lain adalah dengan Dana Kapitasi, melalui Peraturan Presiden Nomor 32 Tahun 2014 tentang Pengelolaan dan Pemanfaatan Dana Kapitasi Jaminan Kesehatan Nasional pada FKTP Milik Pemerintah Daerah. Peraturan ini dimanfaatkan oleh Kabupaten Manggarai Barat, yang telah menerbitkan PERBUP No.32 tahun 2016, tentang Pemanfaatan Dana Kapitasi dan Non Kapitasi Jaminan Kesehatan Nasional pada Unit Pelaksana Teknis Dinas (UPTD) Dinas Kesehatan Kabupaten Manggarai (Bupati Manggarai, 2016). Dinyatakan bahwa dalam hal obat 
dan BMHP yang dibutuhkan tidak tercantum dalam Formularium Nasional sebagaimana dimaksud pada ayat (5), dapat menggunakan obat lain termasuk $\mathrm{OHT}$ dan fitofarmaka secara terbatas, dengan persetujuan kepala Dinas.

\section{Kesiapan klinisi dalam pelayanan OT di RS}

Rumah Sakit Islam Sultan Agung sebagai Rumah Sakit Pendidikan non pemerintah, dipilih karena selama ini dikenal sebagai rumah sakit yang menyelenggarakan pelayanan OT. Narasumber direktur yanmedik dari rumah sakit menyampaikan bahwa ada kesulitan menggunakan OT dalam pelayanan. Disampaikan usulan bahwa-obat tradisional agar dilayankan sebagai upaya preventif, karena selama ini belum digarap, tidak masuk ke kuratif, masuk di pelayanan melalui komite medik dan mengikuti alur yang ditetapkan oleh RS. Pemilihan OT berdasarkan rekomendasi dari organisasi profesi, misalnya Perkumpulan Endokrinologi Indonesia, menetapkan OT keluhan diabetes; Perkumpulan Gastroenterologi Indonesia, untuk keluhan gastro. Catatan penting dari Komite Medik bagi industri OT adalah, bahwa jumlah subyek penelitian dalam uji klinis masih dianggap kurang. Dengan demikian, bila akan masuk ke fasyankes, OT tidak digunakan sebagai terapi utama, namun bersifat komplementer atau sebagai adjuvant.

Kepala Bagian Farmasi Rumah Sakit mengatakan bahwa pengadaan Obat tradisional pada awal tahun 2010, masih dengan struktur pendaanaan dari managemen RS, dan berkembang menjadi pembiayaan konsinyasi dengan industri khususnya di Jateng. Pengadaan OT fitofarmaka, OHT dan jamu tidak dipisahkan, namun digabungkan dengan instalasi farmasi. Tahun 2014, ketika BPJS sudah diterapkan, pengadaan obat sudah masuk sistem dengan acuan FORNAS. Pengadaan diluar FORNAS, harus atas persetujuan Komite Medik. Menentukan apa yang dimasukkan dalam Formularium RS juga menjadi dilema, karena menjadi conflict of interest. Pengadaan langsung dengan pembelian sesuai kebutuhan, atas kebijakan pimpinan, karena sebetulnya jatah pembelian obat herbal tidak ada. Usulan bila kedepan BPJS dapat menjamin OT, dapat dipertimbangkan untuk pasien kanker, penderita shcizofrenia dan diabetes, serta pelancar ASI.

Peraturan yang digunakan adalah Permenkes No. 71 tahun 2013 tentang Pelayanan Kesehatan pada Jaminan Kesehatan Nasional. Pasal 24 dinyatakan bahwa dalam hal obat yang dibutuhkan sesuai indikasi medis pada fasilitas kesehatan rujukan tingkat lanjutan (FKRTL), obat yang tidak tercantum dalam FORNAS, dapat digunakan obat lain berdasarkan persetujuan Komite Medik dan kepala/direktur rumah sakit. Kepala farmasi rumah sakit menyatakan :

"Farmasi rumah sakit hanya tergantung pada apa yang diusulkan dokter. Jika sudah diketahui data produsen, proses menetapkan formularium $R S$ dilakukan selama 3 bulan. Jika klinis mau pakai, paling tidak kemenkes memaksakan menggunakan herbal, tidak hanya menyarankan, dan dibayar BPJS".

Dilanjutkan pernyataan bahwa "Untuk integrasi obat tradisional, formularium obat tradisional nasional ditunggu terbitnya. Hampir sama dengan pelayanan kesehatan lain, aturan atau payung hukum sudah disiapkan". Hal ini merupakan kebutuhan terhadap adanya PMK No. 37 tahun 2017 tentang Pelayanan Kesehatan Tradisional Integrasi yang dapat dilayankan di fasyankes. Dalam PMK ini dijelaskan bahwa obat tradisional dapat digunakan bersama obat konvensional, namun sudah harus terbukti secara ilmiah. Untuk pelayanan herbal di fasyankes PMK 121 tahun 2008 merupakan acuan yang digunakan, namun dianggap kurang kuat dan diharapkan segera terbit revisi menjadi permenkes.

Wawancara dilakukan juga di RSUD K.R.M.T Wongsonegoro Kota Semarang. Narasumber dari komite medik menyampaikan bahwa:

"Pengadaan obat di Rumah Sakit diawasi oleh $K P K$, harus ada dasarnya, sehingga setelah era BPJS, obat herbal hancur, dokter hanya boleh meresepkan obat yang ada di FORNAS". Hal ini menunjukkan bahwa Formularium untuk OT sudah harus disiapkan, sehingga dikemudian hari bila obat tradisional dapat dijamin oleh BPJS, maka proses pengadaan dapat dilakukan secara formal. Terkait dengan OT yang dibutuhkan oleh RS untuk dapat dimasukkan dalam formularium obat tradisional adalah bahwa OT harus memenuhi beberapa faktor yaitu memenuhi ketersediaan, efisien dengan harga yang terjangkau dan untuk penggunaan kronis. Beberapa kebutuhan OT adalah khusus untuk ibu habis melahirkan (pelancar ASI); kebutuhan khusus untuk pasien laki-laki dengan komplikasi hipertensi dengan diabetes untuk memperbaiki kondisi neuropati, dan kebutuhan khusus untuk anak-anak untuk penambah nafsu makan. Selain itu OT diusulkan 
sebagai komplemen atau adjuvant untuk pasien lansia, gangguan fungsi hati, penambah nafsu makan, produk albumin (dari ikan gabus); produk ekstrak cacing (sebagai trombolitik).

Lebih lanjut dikatakan bahwa agar OT diterima oleh tenaga medis di fasyankes diperlukan regulasi untuk memaksakan penggunaan OT. Untuk itu perlu dibangun mind set tenaga medis, agar membuka wawasan dalam menggunakan OT. Seharusnya fitofarmaka sudah dipercaya, karena sudah memiliki bukti ilmiah (evidence based), namun masih terjadi benturan yang berasal dari Komite Medik RS karena masih menganggap bahwa bukti klinis harus jelas secara ilmiah. Implementasi yang telah dilakukan di rumah sakit ini adalah pelayanan akupunktur medik. Keuntungan yang didapatkan adalah pengurangan beberapa hari perawatan, pengurangan penggunaan alat, pengurangan biaya makan dan pengurangan biaya visit. Hal ini sangat menguntungkan bagi kedua belah pihak, yaitu pasien dan rumah sakit.

\section{Dukungan pemerintah daerah terhadap pelayanan obat tradisional}

Dinas Kesehatan Provinsi Jawa Tengah mengatakan bahwa 2-3 tahun yang lalu, rumah sakit mendukung pelayanan OT. Usulan OT berasal dari kabupaten, diteruskan ke provinsi sebagai pihak yang menyediakan. Produk OT yang telah tersedia, kemudian dikirimkan /diberikan ke kabupaten/kota. Penyediaan OT di puskesmas melalui Anggaran Pendapatan dan Belanja Daerah (APBD). Kebijakan tersebut saat ini sudah tidak berjalan karena Dinas Kesehatan Kota (DKK) mengadakan sendiri. Terkait pengadaan OT, beberapa kabupaten/kota yaitu Kabupaten Semarang, Kota Surakarta sebelum adanya BPJS, banyak yang melakukan pelayanan OT. Adanya pelayanan OT tentunya juga berdampak pada peningkatan perekonomian masyarakat melalui produk jamu hasil industri OT di di Jawa Tengah. Sejak diberlakukannya BPJS, sistem tersebut tidak berjalan.

Sementara narasumber dari Dinas Kesehatan Kota Surakarta yang diwakili kabid Yankes dan didampingi oleh dokter Saintifikasi Jamu di salah satu Puskesmas mengatakan sangat mendukung adanya penggunaan OT di puskesmas (termasuk sarana, prasarana, SDM dan pendanaan). Pada prinsipnya pemerintah daerah mendukung penggunaan OT, terdapat pengembangan proyek percontohan di dua puskesmas, yaitu Puskesmas Purwosari dan
Puskesmas Nguter. Kedua puskesmas tersebut memiliki SDM dokter yang sudah ikut pelatihan saintifikasi jamu, akupuntur dan akupresur. Dikatakan juga bahwa "pendanaan untuk obat tradisional tidak masalah, kita ada dana APBD untuk pengadaan obat yang cukup besar". Dengan pernyataan ini dapat dikatakan bahwa sebetulnya dana untuk penyediaan jamu di Puskesmas bisa menggunakan anggaran APBD, tidak perlu menggunakan dana kapitasi. Namun hal ini juga tergantung pada minat dari pengambil keputusan, apakah mendukung atau tidak dalam memanfaatkan OT di puskesmas. Hal ini didukung oleh pernyataan kembali bahwa dalam persiapan pelayanan kesehatan tradisional integrasi sesuai PMK no 37 tahun 2017, penggunaan OT sebagai pelengkap sementara ini sudah ada, beberapa OHT telah disediakan.

Walaupun demikian, masih ada kendala yang dirasakan oleh dokter Saintifikasi Jamu di puskesmas, bahwa dalam implementasi pelayanan OT, bahwa "Harga obat tradisional yang mahal dan persyaratan ketersediaan obat generik/FORNAS minimal $90 \%$ “.

OT yang disediakan adalah jenis OHT, yaitu obat simtomatik seperti pegel linu, obat batuk, penambah nafsu makan, kurkuma (untuk gizi kurang dan terapi Tb), jamu masuk angin dan jamu untuk wasir dan lainnya, diutamakan produk dalam negeri yang sudah terdaftar di BPOM. Fitofarmaka untuk meningkatkan daya tahan tubuh dan untuk tekanan darah tinggi beberapa tahun sebelumnya disediakan di puskesmas, namun karena harga cukup mahal, tidak lagi menjadi pilihan. Biaya obat tradisional diperoleh dari dana DAK yang jumlahnya hanya sedikit yaitu sekitar 600 juta. Kekurangan biaya obat tradisional yang cukup besar dipenuhi dari dana APBD II. Sementara dana kapitasi untuk pembelian OT tidak digunakan, karena pemanfaatannya merupakan kebijakan puskesmas. Biasanya dana kapitasi digunakan untuk obat-obat yang harus ada dengan kebutuhan mendesak (cito), atau untuk obat yang tidak ada di FORNAS.

Penetapan jenis sediaan OT di puskesmas antara lain berdasarkan faktor harga karena harga OT tidaklah murah. Harga beberapa fitofarmaka lebih mahal jika dibandingkan dengan obat konvensional untuk klaim pengobatan yang sama. Akan tetapi bila OT tersebut merupakan pilihan banyak pasien dan selisih harganya lebih mahal sedikit dari obat konvensional, maka puskesmas tetap memasukkan OT tersebut dalam perencanaan, dengan alokasi dana pembelian OT tidak lebih dari $10 \%$ dari total 
anggaran obat. Harga OT menjadi hal yang menarik untuk dibahas. Perbandingan harga OT dengan obat konvensional cukup bervariasi, bisa lebih mahal ataupun lebih murah. Contoh OT dengan harga lebih murah dari obat konvensional misalnya untuk keluhan hemoroid, produk OT untuk wasir (OHT) harganya Rp. 20.000/strip (10 tablet), sementara produk konvensional harganya Rp.50.000/strip. Produk OT pelancar ASI, harganya Rp 76.000/30 kaplet, sementara Moloco B12 (pelancar ASI konvensional) harganya Rp. 4.000/ tablet. Contoh OT yang lebih mahal dari obat konvensional adalah fitofarmaka untuk DM dengan harga Rp. 33.000/strip, sementara glibenklamid Rp. 250,- per tablet; fitofarmaka untuk hipertensi harga Rp. 44.000 per pak isi 30 kapsul (sekitar Rp. 1.500,- per kapsul), sedangkan obat generik Amlodipine harga Rp. 15.000 per box isi 5 strip (50 tablet), sehingga bila mempertimbangkan faktor harga terjangkau, maka tidak mungkin dapat memenuhi syarat. (sumber media elektronik)

\section{Hasil analisis induktif}

Adanya BPJS menyebabkan pemanfaatan OT di fasyankes menurun, meskipun sebenarnya fasilitas pelayanan kesehatan mendukung adanya pelayanan obat tradisional. Pelayanan OT memerlukan suatu daftar obat tradisional yang dapat digunakan sebagai acuan dokter untuk memanfaatkan OT dalam upaya preventif dan promotif serta kuratif keluhan ringan dan paliatif. Pengunaan OT sebagai komplementer dengan obat konvensional, dapat meningkatkan atau mempercepat penyembuhan.

Penyediaan OT yang dilayankan di fasyankes dapat berupa fitofarmaka, sediaan OHT bahkan jamu yang dianggap sangat diperlukan untuk klaim tertentu, berdasarkan berbagai pertimbangan. Komite medik di rumah sakit mengharapkan adanya OT dengan bukti ilmiah yang kuat, bila akan digunakan untuk terapi, namun sementara ini pemanfaatan sebagai adjuvant dapat diterima. Pembiayaan OT dapat dilakukan melalui DAK atau kapitasi, namun memerlukan suatu ketetapan dari pemerintah agar semua fasilitas pelayanan kesehatan memanfaatkan obat tradisional. Komite Medik mengharapkan bahwa OT terpilih adalah yang dibutuhkan untuk pelayanan kesehatan untuk upaya preventif, promotif, kuratif ringan dan paliatif yang tercantum dalam formularium daftar obat tradisional yang ditetapkan oleh Menteri, baik sebagai komplemen atau adjuvant.

\section{PEMBAHASAN}

Peraturan dan perundangan yang dikaji telah dibagi dalam 3 kelompok yaitu tentang kebijakan nasional, pelayanan dan ketersediaan. Terkait dengan pemanfaatan OT, terdapat Kebijakan Obat Tradisional (Kep Menkes No. 381/MENKES/SK/III/2007) yang salah satu tujuannya adalah tersedianya obat tradisional yang terjamin mutu, khasiat dan keamanannya, teruji secara ilmiah dan dimanfaatkan secara luas baik untuk pengobatan sendiri maupun dalam pelayanan kesehatan formal. Saat ini sudah 13 tahun berjalan, perkembangan pelayanan di fasyankes belum terlihat perkembangannya, terutama setelah adanya BPJS. Peraturan terkait pelayanan, KMK No. 121/2008 tentang Standar Pelayanan Medik Herbal; PP 103 tahun 2014; Permenkes nomor 37 tahun 2017 tentang Pelayanan Kesehatan Tradisional Terintegrasi, ketiganya diperuntukkan untuk pelayanan OT di fasyankes, dan belum sepenuhnya dimanfaatkan. Dalam hal ketersediaan adanya Permenkes Nomor 82 Tahun 2015 Tentang Pemanfaatan Dana DAK; Permenkes Nomor 21 Tahun 2016 Tentang Penggunaan Dana Kapitasi Jaminan Kesehatan Nasional Untuk Jasa Pelayanan Kesehatan dan Dukungan Biaya Operasional Pada Fasilitas Kesehatan Tingkat Pertama Milik Pemerintah Daerah merupakan pengaturan tentang penggunaan dana yang dapat digunakan untuk pengadaan obat tradisional. Pelayanan terkait OT yang disiapkan pemerintah sudah cukup lengkap, namun upaya mendorong terintegrasinya OT di fasyankes masih ditemukan kendala.

Di beberapa negara berkembang, pengobatan tradisional adalah salah satu sumber utama perawatan kesehatan. Biasanya negara-negara ini mempunyai keterbatasan akses layanan kesehatan berbasis obat konvensional. Contoh, di negara Afrika penggunaan OT cukup luas, dapat dikaitkan dengan ketersediaannya dan harganya yang terjangkau (Zhang, 2015). Penggunaan OT di Afrika sebagai terapi alternatif atau komplementer, untuk manangani berbagai penyakit seperti hipertensi, diabet, kanker, asma, malaria hingga kelainan mental (Jameset al., 2013).Obat tradisional Afrika dan praktisi kesehatan tradisional telah memberikan kontribusi yang signifikan terhadap pencapaian cakupan kesehatan universal (UHC) (Kasilo et al. 2019). Di negara yang lebih maju, pemanfaatan OT dipengaruhi budaya dan sejarah. Singapura dan Republik Korea mempunyai 
perawatan kesehatan konvensional cukup mapan, namun 76 persen dan 86 persen dari populasi masing-masing juga menggunakan OT. Di beberapa negara khususnya dengan penghasilan tinggi dengan struktur sistem kesehatan sudah baik, OT digunakan sebagai terapi pelengkap atau ajuvant (Zhang, 2015).

WHO telah menetapkan konsep integrasi seiring dengan meningkatnya Traditional \& Complementary Medicine (T\&CM) dalam sistem kesehatan (WHO, 2013). Di antara 37 negara dan daerah di Wilayah Pasifik Barat, negara seperti Cina, Jepang, dan Republik Korea telah mempunyai kebijakan integrasi yang berkembang dengan baik dan menerapkan sistem pengaturan untuk produk, praktik, praktisi dan sistem pendidikannya. Negara-negara ini mengakui dan melembagakan T\&CM melalui dukungan politik yang kuat dan didukung oleh undang-undang. Sementara negara dalam proses mengembangkan integrasi di dalam sistem kesehatannya adalah negara yang cenderung memiliki sejarah panjang penggunaan OT, tetapi belum mencapai tingkat dukungan dan pelembagaan seperti terlihat di negara mapan. Malaysia sedang dalam proses membangun dan menerapkan sistem pengaturan T\&CM yang mencerminkan beragam bentuk T\&CM yang dipraktikkan (Oliver, 2016).

Indonesia termasuk sebagai negara menuju integrasi, seperti yang tertuang dalam roadmap pengembangan jamu nasional, dan diharapkan dapat tercapai dalam tahun 2025. Di Indonesia, konsep integrasi terdapat dalam Permenkes No. 37 tahun 2017 tentang pelayanan kesehatan tradisional integrasi antara pelayanan kesehatan tradisional dan konvensional. Sementara pelayanan khusus OT sendiri sebetulnya dapat dilayankan dengan dasar kepmenkes pelayanan medik herbal, namun hingga saat ini belum berjalan karena tidak dilengkapi dengan daftar produk OT yang dapat dilayankan. Pembiayaan OT telah difasilitasi melalui dana DAK atau kapitasi, atau APBN tk II. Dalam kenyataan di lapangan, hal ini tidak dimanfaatkan oleh fasyankes, karena tidak ada ketetapan bagi fasyankes untuk menggunakan OT, political will dari pemerintah seperti pada negara maju, masih kurang kuat. Contoh yang terjadi, akupunktur terapis sebagai yankestrad semula dijamin ASKES, dan dijamin BPJS, kemudian hilang sebagai jaminan pembiayaan BPJS, digantikan oleh akupunktur medis (Jonathan, Dharmawan, 2019). Kondisi ini masih menjadi masalah mengingat banyaknya pihak yang mengharapkan akupunktur tidak hanya dibatasi untuk akupunktur medis saja. Dalam sistem integrasi, akupunktur dapat dilayankan sebagai komplementer dengan obat konvensional atau komplementer dengan OT. Sebagai gambaran pelayanan akupunktur di beberapa negara, dari 133 negara yang dalam sistem kesehatannya melayankan kesehatan tardisional, sebanyak 50 negara menjamin pembiayaan pelayanan akupunktur dan 13 negara telah menjamin pembiayaan pelayanan dengan OT(World Health Organization, 2019).

Produk OT yang dapat dilayankan di fasyankes masih perlu dikaji dan diatur untuk jangka waktu paling tidak 5 tahun ke depan sesuai dengan target roadmap pengembangan jamu. Beberapa hasil penelitian dapat dijadikan contoh kendala yang masih perlu mendapat perhatian. Suatu penelitian menunjukkan bahwa $70,9 \%$ dari 46 pasien hipertensi di puskesmas, menggunakan jamu selain obat konvensional (Paramita et al., 2017). Dalam penelitian ini, jamu yang digunakan oleh masing-masing pasien berbeda sesuai dengan kepercayaaan dan pemahamannya, dan disayangkan tidak menggunakan OHT atau fitofarmaka. Fitofarmaka adalah produk dengan evidence base, dan seharusnya layak digunakan dalam fasyankes. Hasil survei, komunikasi terapetik pada tenaga medis dalam menyampaikan informasi tentang manfaat OT adalah berdasarkan evidence base (Prasanti, 2017). Wawancara mendalam pada 9 orang pasien diabetes di Poliklinik Obat Tradisisional Indonesia (OTI), menunjukkan bahwa penderita diabetes cenderung menggunakan lebih dari 1 pengobatan dengan menambahkan jamu untuk kesembuhan (komplementer) (Joeliantina et al, 2016). Suatu wawancara mendalam terhadap 69 pasien diabetes, $42 \%(n=29)$ telah menyatakan manfaat pengobatan komplementer. Survei lain terhadap pasien diabetes dengan pengobatan komplementer, menganggap bahwa pengobatan konvensional untuk diabetes kurang efektif, namun dengan komplementer dianggap lebih aman, efek samping lebih sedikit (Canaway et al., 2014). Penelitian untuk menilai perilaku dokter ahli penyakit dalam (subyek 660 orang) terhadap pengobatan komplementer dilakukan di USA, menunjukkan data bahwa $76 \%$ dokter tidak pernah menyarankan pasiennya untuk menjalani terapi komplementer, namun $44 \%$ dokter menyatakan merujuk pasiennya ke praktisi komplementer apabila tersedia fasilitas ini di institusi kerja mereka. Kerja sama dengan praktisi komplementer menunjukkan efek positif dan mempercayai bahwa terapi komplementer akan 
meningkatkan jumlah kunjungan(Spiteri et al., 2013). Terapi komplementer dianggap tepat untuk penyakit kronik atau degeneratif, karena dianggap adanya penurunan fungsi organ, sehingga perlu pengobatan menyeluruh (holistik). Hal ini ditunjukkan dari evaluasi praktik dokter pelayanan jamu untuk penyakit degeneratif, terbanyak adalah untuk diabetes mellitus, diikuti oleh kolesterol dan hipertensi (Widowati L.dkk., 2014).

Terkait dengan UU No. 29 tahun 2004 tentang Praktik Kedokteran, bahwa sediaan yang dapat dilayankan di fasyankes adalah yang telah memiliki evidence base. Produk Fitofarmaka adalah yang layak masuk dalam fasyankes, namun tidak menutup kemungkinan penggunaan OHT atau jamu yang memang sangat dibutuhkan upaya sebagai upaya preventif, promotif, kuratif ringan dan paliatif baik sebagai pendamping atau pengganti. Beberapa hal yang dapat menjadi pertimbangan untuk memilih OT tersebut adalah belum ada/terbatasnya obat konvensional untuk suatu keluhan; klaim dan ketersediaan fitofarmaka atau OHT; efektifitas serta harga.

Pemanfaatan OT di fasyankes dapat mendukung ketahanan sistem kesehatan yang berkelanjutan, contohnya adalah dalam menghadapi wabah penyakit atau bencana. Saat wabah penyakit menular terjadi dimana biomedis tidak dapat memecahkan masalah kesehatan, negara-negara mapan dan dengan sistem integrasi cenderung mengeksplorasi opsi memanfaatkan kesehatan tradisional. Sebagai contoh, China selama wabah SARS (sindrom pernapasan akut berat) menggabungkan dengan kesehatan tradisional, di beberapa daerah menunjukkan hasil positif (walaupun belum meyakinkan), antara lain kontrol yang lebih baik terhadap demam, menghilangkan gejala, dan pengurangan konsumsi steroid (Park, 2019; Canaway. 2014). Demikian pula saat ini. dengan terjadinya pandemi covid-19, hampir seluruh negara di dunia berusaha mencari vaksin atau obatnya. Dalam keadaan tidak menentu, pakar dibidang herbal di Indonesia menyatakan bahwa "emponempon" dapat digunakan untuk preventif. Temulawak, jahe dan kunyit sebagai kelompok "empon-empon" termasuk 3 tanaman obat yang banyak digunakan oleh masyarakat dan dimanfaatkan oleh hampir $60 \%$ masyarakat usia >17 tahun (Nurhayati, Widowati L., 2017; Aryanti dkk., 2019). Beberapa OT bermanfaat untuk membantu meningkatkan daya tahan tubuh, baik dalam bentuk OHT maupun fitofarmaka. Sebagai langkah percepatan, sudah selayaknya OT atau jamu untuk meningkatkan daya tahan tubuh dilayankan difasilitas rumah sakit rujukan dan tentunya dengan jaminan pembiayaan.

Sebelum tersedianya Formularium Obat Tradisional Nasional (Fortranas), kebutuhan mendesak fasyankes adalah tersedianya daftar obat tradisional. Tentunya menetapkan daftar obat tradisional, dapat berdasarkan berbagai literatur/ artikel dan bukti ilmiah. Tahun 2013, negara Malta di Eropa telah menyusun Formularium herbal dari produk yang sudah teregistrasi, dan menjadi acuan bagi apoteker atau tenaga medis untuk memberikan peresepan herbal berbasis bukti (Spiteriet al., 2013).

\section{KESIMPULAN DAN SARAN}

\section{Kesimpulan}

Pelayanan dengan obat tradisional masuk jalur upaya preventif, promotif atau kuratif ringan baik sebagai adjuvant maupun komplemen dengan obat konvensional. Pembiayaan obat tradisional dapat dilakukan dengan DAK, dana Kapita si atau APBN II, namun belum dimanfaatkan. Kondisi ini karena kurangnya political will dari stake holder dan belum adanya acuan standar Formularium Obat Tradisional, terutama jika kemudian hari dapat dijamin oleh BPJS. Masih dibutuhkan adanya regulasi ketetapan menteri bahwa fasyankes wajib melakukan pelayanan dengan obat tradisional.

\section{Saran}

Dilakukan penelitian untuk mendapatkan model standar pelayanan obat tradisional bersama daftar obat tradisional yang bersifat nasional, sehingga dapat digunakan sebagai acuan tenaga kesehatan dalam pelayanan obat tradisional dan potensi pembiayaan dengan BPJS.

\section{UCAPAN TERIMA KASIH}

Ucapan terima kasih tak terhingga kami sampaikan kepada Dinas Kesehatan Provinsi Jawa Tengah, Dinas Kesehatan Kota Surakarta, Rumah Sakit Islam Sultan Agung Semarang, RSUD K.M.R.T Wongsonegoro Kota Semarang; Puskesmas Wonosari Surakarta, atas kesediaan dan penerimaan tim Kajian untuk melakukan wawancara mendalam. 


\section{DAFTAR PUSTAKA}

Alawiya N., U. N. A. . and U., A. (2017) 'Implementasi legalisasi pelayanan kesehatan tradisional di Kabupaten Banyumas sebagai bentuk perlindungan hukum bagi masyarakat', in Prosiding Seminar Nasional dan Call for Papers "Pengembangan Sumber Daya Perdesaan dan Kearifan Lokal Berkelanjutan VII"1718 November 2017 Purwokerto", pp. 1479-1485. Available at: http://jurnal.Ippm.unsoed.ac.id/ojs/index. php/Prosiding/article/viewFile/492/463.

Aryanti P.I, Haryanto J., Ulfiana E.(2018) 'Red Ginger (Zingiber officinale var. rubrum ) massage reduces stiffness and functional Disability in Elderly with Osteoarthritis', Jurnal Ners, 13(2). doi: doi:http:// dx.doi.org/10.20473/jn.v13i2.929.

Canaway, R., Manderson, L. and Oldenburg, B. (2014) 'Perceptions of benefit of complementary therapy use among people with diabetes and cardiovascular disease', Forschende Komplementärmedizin / Research in Complementary Medicine', (February). doi: $10.1159 / 000358725$.

Darma S. (2013) 'Complementary and alternative medicine (CAM): Fakta Atau Janji', Idea Nursing Jo u rn a I, 4(3).

Delima, Widowati L., Astuti Y., Siswoyo H., Gitawati R., P. A. (2012) 'Gambaran praktik penggunaan jamu oleh dokter di enam provinsi di Indonesia.', Buletin Penelitian Kesehatan, 40(3), pp. 109-122.

Grace, R., Vaz, J. and Da Costa, J. (2020) 'Traditional medicine use in Timor-Leste', BMC Complementary Medicine and Therapies. BMC Complementary Medicine and Therapies, 20(1),. 1-6. doi: 10.1186/ s12906-020-02912-9.

Gyasi, R. M. et al. (2011) 'Public perceptions of the role of traditional medicine in the health care delivery system in Ghana', Global Journal of Health Science, 3(2). doi: 10.5539/gjhs.v3n2p40.

James, P. B. et al. (2018) 'Traditional , complementary and alternative medicine use in Sub-Saharan Africa: a systematic review', BMJ Global Health. doi: 10.1136/ bmjgh-2018-000895.

Joeliantina, A. et al. (2016) 'Responses of diabetes mellitus patients who used complementary medicine', International Journal of Public Health Science (IJPHS), 5(4), p. 367. doi: 10.11591/ijphs.v5i4.4831.

Jonathan I., D. D. (2019) 'Kepastian hukum pelayanan kesehatan akupunktur dalam program jaminan kesehatan nasional', Jurnal Terpadu IImu Kesehatan, 8(1), pp. 01-129. Available at: http://jurnalinterest. com/index.php/int/article/download/111/109/.

Kasilo, O. M. J. et al. (2019) 'Towards universal health coverage: Advancing the development and use of traditional medicines in Africa', BMJ Global Health, 4. doi: 10.1136/bmjgh-2019-001517.
Kemenko Perekonomian (2019) 'Roadmap Pengembangan Jamu', in Journal of Chemical Information and Modeling. Percetakan IPB, Bogor, pp. 1689-1699.

Manggarai_Barat, B. (2015) 'PERBUP MANGGARAI BARAT NO. 32 TAhun 2016'.

Media Indonesia, 9 Maret 2020 (no date) 'BERITA INDUSTRI Industri Herbal Indonesia Berprospek Cerah'. Available at: http://www.kemenperin.go.id/ artikel/3109/Industri-Herbal-Indonesia- BerprospekCera.

Nsagha, D. S. et al. (2020) 'The Role of Traditional, Complementary / Alternative Medicine in Primary Healthcare , Adjunct to Universal Health Coverage in Cameroon: A Review of the Literature', American Journal of Epidemiology and Infectious Disease, Vol. 8, No(April), pp. 37-47. doi: 10.12691/ajeid-8-1-6.

Nurhayati and Widowati L. (2017) 'The use of traditional health care among Indonesian Family', Health Science Journal of Indonesia, 8(1), pp. 30-35. doi: 10.22435/hsji.v8i1.5600.Nurhayati.

Oliver, S. J. (2013) 'The role of traditional medicine practice in primary health care within Aboriginal Australia: A review of the literature', Journal of Ethnobiology and Ethnomedicine, 9(1), pp. 1-8. doi: 10.1186/17464269-9-46.

Paramita, S. et al. (2017) 'Pola penggunaan obat bahan alam sebagai terapi komplementer pada pasien hipertensi di puskesmas', Jurnal Sains dan Kesehatan, 1(7), pp. 367-376. doi: 10.25026/jsk.v1i7.56.

Park, Y. L. and Canaway, R. (2019) 'Integrating traditional and complementary medicine with national healthcare systems for universal health coverage in asia and the Western Pacific', Health Systems and Reform. Taylor \& Francis, 5(1), pp. 24-31. doi: 10.1080/23288604.2018.1539058.

Prasanti, D. (2017) 'Komunikasi terapeutik tenaga medis dalam pemberian informasi tentang obat tradisional bagi masyarakat', Mediator: Jurnal Komunikasi, 10(1), pp. 53-64. doi: 10.29313/mediator.v10i1.2624.

Rubiyanti, R. (2019) 'Hubungan sikap dan hambatan terhadap persepsi mahasiswa farmasi tentang complementary and alternative medicine (CAM)', Jurnal IImiah Farmasi, 15(1), pp. 28-36. doi: 10.20885/ jif.vol15.iss1.art4.

Siswanto, S. (2018) 'Pengembangan kesehatan tradisional Indonesia: Konsep, Strategi dan Tantangan', Jurnal Penelitian dan Pengembangan Pelayanan Kesehatan, 1(1), pp. 17-31. doi: 10.22435/jpppk.v1i1.429.

Spiteri, M. et al. (2013) 'Compilation of a herbal medicine formulary for herbal substances in Malta and its usefulness amongst healthcare professionals', Journal of Young Pharmacists. Elsevier Ltd, 5(1), pp. 22-25. doi: 10.1016/j.jyp.2013.01.003.

Suharmiati, S. et al. (2018) 'Studi kesesuaian sumber daya dengan pelayanan kesehatan tradisional Rumah Sakit Pemerintah di Provinsi DI Yogyakarta, Jawa Tengah 
Kajian Kebijakan Pemanfaatan Obat Tradisional (Lucie Widowati, dkk.)

dan Jawa Timur', Jurnal Kefarmasian Indonesia, 8(1), pp. 64-75. doi: 10.22435/jki.v8i1.7672.64-75.

Widayanti, A. W. et al. (2020) 'Health-seeking behavior of people in Indonesia: A narrative review', Journal of Epidemiology and Global Health, 10(1), pp. 6-15. doi: 10.2991/jegh.k.200102.001.

World Health Organization (WHO) (2013) 'WHO Traditional Medicine Strategy 2014-2023', in.
World Health Organization (WHO) (2019) WHO global report on traditional and complementary medicine. Available at: https://apps.who.int/iris/bitstream/hand le/10665/312342/9789241515436-eng.pdf?ua=1

Zhang, Q. (2015) 'Traditional and complementary medicine in primary health care', in Alexander Medcalf, Sanjoy Bhattacharya, H. M. M. S. and M. J. (ed.) Health For All : The Journey of Universal Health Coverage. Orient Blackswan Private Limited 3-6-752, pp. 93-98. doi: 10.26530/oapen_576912. 